Heredity (1979), 42 (2), 125-132

\title{
THE GENETICAL CONTROL OF COLD RESISTANCE AND VERNALISATION REQUIREMENT IN WHEAT
}

\author{
CHRISTINE CAHALAN* and C. N. LAW \\ Plant Breeding Institute, Trumpington, Cambridge
}

Received 9.x.78

\begin{abstract}
Summary
Vernalisation response in wheat is controlled by genes located on chromosomes $5 \mathrm{~A}$ and 5D. The variety Chinese Spring has a winter or late allele (vrnl) on chromosome $5 \mathrm{~A}$ and a spring or early allele $(\operatorname{Vrn} 3)$ on $5 \mathrm{D}$. Increasing the dosage of the former has no significant effect on vernalisation response, but when the dosage of the latter is increased the response is reduced and flowering takes place earlier in unvernalised plants. A background of alien cytoplasm from Aegilops ovata prolongs the vegetative phase of development and also increases the vernalisation response, although to a lesser extent than chromosomal changes.

The same chromosomes are involved in the control of cold resistance. Alleles on 5A and 5D of Chinese Spring condition poor tolerance to low temperatures, while those on 5A of Cheyenne and 5D of Hope confer a higher degree of resistance. Cytoplasmic as well as chromosomal factors play an important part in determining the level of resistance of difference genotypes.

Within the group of genotypes studied, there is no statistically significant relationship between vernalisation response and resistance to freezing to temperatures of $-6^{\circ}$ and $-12^{\circ} \mathrm{C}$, so that in spite of the fact that chromosomes of of homoeologous group 5 are implicated in the control of both vernalisation requirement and cold resistance there is no evidence that the characters are determined by the same genetic factors.
\end{abstract}

\section{INTRODUCTION}

Autumn-sown or winter forms of the hexaploid bread wheat, Triticum aestivum $L$. $(2 n=6 x=42)$, require a period of low temperatures if they are to flower and mature successfully. This vernalisation requirement is slight or absent in spring wheats, which are sown early in the year. Winter wheats tend also to be more tolerant of cold and frost than spring varieties. This tolerance may be a consequence of vernalisation requirement. Since juvenile plants are less susceptible to cold than older ones, a need for vernalisation before development can proceed may hold plants at a stage where they have good resistance; alternatively, satisfying a requirement may necessitate exposure to temperatures so low that plants would not survive unless they possessed a measure of cold resistance.

Genetic control of the vernalisation response has been investigated by several workers. Pugsley $(1971,1972)$ found that spring-winter growth habit is governed by at least four genes, designated Vrn1, Vrn2, Vrn3 and $V r n 4$. Using aneuploid and inter-varietal chromosome substitution lines, $V r n 1$ and $V r n 3$ have been located on the long-arms of chromosomes $5 \mathrm{~A}$ and 5D respectively (Law, Worland and Giorgi, 1976; Maystrenko, 1974), whilst possibly an additional locus, $V r n 5$, has been assigned to the short-arm of chromosome 7B (Law, 1966). Other chromosomes have been reported

* Present address: Institute of Terrestrial Ecology, Penicuik, Midlothian, Scotland. $42 / 2-\mathrm{A}$ 
as having minor effects on vernalisation requirement (Law, Otlowska and Worland, 1974; Halloran and Boydell, 1967).

Winter-hardiness is a complex character which is almost certainly under polygenic control (Nilsson-Ehle, 1912; Andersson, 1935; Worzella, 1935; Bares, Segeta and Vlasák, 1973). Cold resistance, which is one factor contributing to winter-hardiness, has been shown to be influenced by the chromosomes of homoeologous group 5, and chromosomes $4 \mathrm{D}$ and $7 \mathrm{~A}$ are also implicated in its control (Law and Jenkins, 1970).

The relationship between vernalisation requirement and cold resistance has not been established, and the literature contains conflicting accounts of its nature (e.g. Hayes, 1927; Becker, Fuchs and Japha, 1947; Gulyaev and Magurov, 1973; Martinic, 1974). Although studies using aneuploid and substitution lines suggest a degree of independence in control of the two characters, group 5 chromosomes are certainly important in both, and it could be that the $V r n$ genes on these chromosomes also influence cold resistance. It was to investigate this situation further that the experiments described below were undertaken.

\section{Materials AND methods}

The following eight genotypes were used involving whole chromosome substitutions or additions for homoeologous group 5 in the variety Chinese Spring.

1. Chinese Spring (= CS)

$$
\begin{aligned}
& 2 n=42 \\
& 2 n=42 \\
& 2 n=42 \\
& 2 n=42 \\
& 2 n=44 \\
& 2 n=44 \\
& 2 n=44 \\
& 2 n=44
\end{aligned}
$$

3. CS (Cheyenne 5A)$$
\text { 4. } \mathrm{CS} 5 \mathrm{~A}\left(5 \mathrm{C}^{\mathrm{u}}\right)
$$

5. CS tetrasomic $5 \mathrm{~A}$

7. $\mathrm{CS}$ addition $5 \mathrm{Cu}$

8. $\mathrm{CS}$ addition $5 \mathrm{R}^{\mathrm{k}}$

A ninth line was also included, CS ovata, in which the full chromosome complement of Chinese Spring has been introduced into a background of Aegilops ovata cytoplasm by backcrossing. It was hoped that the study of this line would provide some indication of the role of the cytoplasm in cold resistance and vernalisation requirement. This line was developed to the $\mathrm{BC}^{2}$ (seventh backcross) generation by Dr S. S. Maan of North Dakota State University, U.S.A., and has since been taken to $\mathrm{BC}^{10}$ at the Plant Breeding Institute.

The Hope substitution line CS (Hope 5D), in which chromosome 5D of GS has been replaced by $5 \mathrm{D}$ of Hope, and the two CS tetrasomic lines were developed by Dr E. R. Sears of the University of Missouri, U.S.A., and the Cheyenne substitution line, CS (Cheyenne 5A), carrying 5A of Cheyenne instead of $5 \mathrm{~A}$ of CS, by Dr R. Morris of the University of Nebraska, U.S.A.

CS $5 \mathrm{~A}(5 \mathrm{Cu})$ and $\mathrm{CS}$ addition $5 \mathrm{Cu}$, in which the $5 \mathrm{Cu}^{\mathrm{u}}$ chromosome of Ae. umbellulata has been either substituted for CS 5A or added to CS, were produced at the Plant Breeding Institute by $\mathrm{Mr}$ V. Chapman. The CS addition $5 \mathrm{R}^{\mathrm{k}}$ line, which has an added chromosome from the variety King II of rye, Secale cereale, was also developed at the Plant Breeding Institute. 
CS, CS ovata and the three substitution lines all have a somatic chromosome number of $2 n=42$. The two tetrasomics and two addition lines have $2 n=44$ and are cytologically unstable, tending to revert to the trisomic $(2 n=43)$ condition. Because of this, the chromosome constitutions of some of the progeny from each of the tetrasomic and addition lines were determined from root-tip squashes stained in Feulgen at the completion of the experiments. In this way it was established that one of the CS tetrasomic 5A and one of the CS tetrasomic 5D plants used had reverted to the trisomic condition. The data from these plants were therefore omitted from the analysis of the results.

\section{(i) Vernalisation requirement}

Three replicates of each of the $2 n=42$ genotypes and five of the $2 n=44$ lines were used in each treatment (vernalised or unvernalised), making a total of 82 plants.

For the vernalised treatment, seed was kept on damp filter paper at $4^{\circ} \mathrm{C}$ in the dark for 3 weeks and then sown in $4 \frac{1}{4}$-inch pots which were put in position in a fully randomised design in a controlled environment cabinet. Conditions were set to provide an 8-hour day and a continuous temperature of $8^{\circ} \mathrm{C}$. Two weeks later, unvernalised seed was germinated for 48 hours and sown as before, pots then being placed in position in the randomised layout. Cabinet conditions were set to give a 16-hour day with a continuous temperature of $18^{\circ} \mathrm{C}$, and this regime was maintained until the end of the experiment. The number of days to ear emergence for each individual was recorded.

Estimates of chromosomal effects and their interactions with vernalisation were obtained by comparing each substitution and addition line with Chinese Spring in both the unvernalised and vernalised environments. The full details of the methods used in making these estimations are given below and follow those described previourly by Mather and Jinks (1971).

\begin{tabular}{|c|c|c|c|}
\hline & Unvernalised & Vernalised & Mean \\
\hline \multicolumn{4}{|l|}{ Substitution or addition } \\
\hline line & $\begin{array}{c}m+(d)+e+g \\
(1)\end{array}$ & $\begin{array}{c}m+(d)-e-g \\
\text { (2) }\end{array}$ & $m+(d)$ \\
\hline Chinese Spring (CS) & $\begin{array}{c}m-(d)+e-g \\
(3)\end{array}$ & $\begin{array}{c}m-(d)-e+g \\
(4)\end{array}$ & $m-(d)$ \\
\hline Mean & $m+e$ & $m-e$ & $m$ \\
\hline \multicolumn{4}{|c|}{$\begin{array}{l}\text { where } m=\text { the mid-point } \\
\qquad \begin{aligned}(d)= & \text { the mean genetic difference between either the substituted chromosome } \\
& \text { and its homologue in CS, or the presence and absence of a particular } \\
& \quad \text { chromosome. } \\
e & =\text { mean vernalisation effect. } \\
g & =\text { chromosome-vernalisation interaction. }\end{aligned}\end{array}$} \\
\hline
\end{tabular}

Thus $(d)=\frac{1}{4}[(1)+(2)-(3)-(4)], e=\frac{1}{4}[(1)-(2)+(3)-(4)]$ and $g=$ $\frac{1}{4}[(1)-(2)-(3)+(4)]$ whilst the standard errors of these estimates can be obtained from $\left(\frac{1}{4} V\right)^{t}$ where $V$ is the mean square error of the overall experiment. In the case of CS ovata, $(d)$ refers to the difference between the effects of the ovata and aestivum cytoplasms and $g$ the interaction of this cytoplasmic difference with vernalisation. 


\section{(ii) Cold resistance}

The ability of seedlings to withstand exposure to sub-zero temperatures was investigated using a technique developed by Jenkins and Roffey (1974). This depends upon the observation that the electrical conductance of a plant tissue, irrespective of cereal variety, is normally low and constant but rises as tissues become progressively damaged through freezing. A pilot experiment using four genotypes known to differ in their degree of winterhardiness showed that the best separation of lines was obtained when seedlings were hardened off for 14 days in a growth cabinet operating at a 10 -hour day with day and night temperatures of $8^{\circ} \mathrm{C}$ and $4^{\circ} \mathrm{C}$ respectively and then frozen to a temperature of $-6^{\circ} \mathrm{C}\left(-6^{\circ} \mathrm{C} / 14\right.$-day regime $)$. This and $\mathrm{a}-12^{\circ} \mathrm{C} / 28$-day regime, which gave the next best separation, were used to test the resistance of the nine genotypes under investigation.

For the freezing treatment, plants were placed in a specially constructed tank maintained at $1^{\circ} \mathrm{C}$, the temperature was then reduced over $2 \frac{1}{2}$ hours to $-4.5^{\circ} \mathrm{C}$, where it was held for $7 \frac{1}{2}$ hours before dropping again to the final temperature. This was then maintained for 12 hours and was followed by a 7 -hour thawing period to $1^{\circ} \mathrm{C}$.

Every line was represented by four replicates of five seedlings each, and following freezing the electrical conductance of the first leaf of each seedling was determined. The conductance of plant tissue was measured on the linear volt scale of a standard "Avometer" set at ohms $\times 100$. The value for each replicate was given by the mean conductance of the five seedlings.

\section{Results}

\section{(i) Vernalisation requirement}

The analysis of variance for days to ear emergence is shown in table 1 . Because of the unequal numbers of replicates of the different genotypes, an unadjusted two-way analysis of variance is not applicable, but the data conform to the case where it is possible to use an unweighted analysis of cell means with the error term derived from an adjusted within-cell mean square (Snedecor and Cochran, 1967). Differences between treatments and genotypes as well as the interaction between these two main effects are significant, indicating that vernalisation affects the processes which determine the date of ear emergence and that the substitution or addition of single chromosomes of homoeologous group 5 into Chinese Spring can considerably influence the character.

\section{TABle 1}

Analysis of variance of the number of days to ear emergence in nine wheat genotypes grown in a 16-hour day at $18^{\circ} \mathrm{C}$

\begin{tabular}{|c|c|c|c|}
\hline Item & d.f. & M.S. & V.R. \\
\hline Vernalised $v$. unvernalised & 1 & 4297.88 & $3384 \cdot 16 * * *$ \\
\hline Genotypes & 8 & $239 \cdot 89$ & $188 \cdot 77 * * *$ \\
\hline $\begin{array}{l}\text { Genotypes/vernalised } v \text {. } \\
\text { unvernalised }\end{array}$ & 8 & $108 \cdot 21$ & $85 \cdot 20 * * *$ \\
\hline Error & 50 & $1 \cdot 27$ & - \\
\hline
\end{tabular}


TABLE 2

Estimates of genetic effects (d), vernalisation effects, e, and genotype/vernalisation interaction ( $\mathrm{g}$ ), for eight wheat genotypes compared with Chinese Spring for the number of days to ear emergence

\begin{tabular}{lllll}
\multicolumn{1}{c}{ Genotype } & & $(d)$ & $e$ & $(g)$ \\
CS ovata & $(+)$ & $12 \cdot 83 * * *$ & $16 \cdot 17 * * *$ & $2 \cdot 33 * * *$ \\
CS (Hope 5D) & $(+)$ & $12 \cdot 10^{* * *}$ & $22 \cdot 08 * * *$ & $9 \cdot 75 * * *$ \\
CS (Cheyenne 5A) & $(+)$ & $1 \cdot 08$ & $14 \cdot 42 * * *$ & $0 \cdot 58$ \\
CS 5A (5Cu) & $(+)$ & $1 \cdot 53 *$ & $13 \cdot 67 * * *$ & $-0 \cdot 17$ \\
CS tetrasomic 5A & $(+)$ & $2 \cdot 18^{* * *}$ & $14 \cdot 28 * * *$ & $0 \cdot 45$ \\
CS tetrasomic 5D & $(-)$ & $2 \cdot 48 * * *$ & $10 \cdot 71 * * *$ & $3 \cdot 13 * * *$ \\
CS addition 5C & $(+)$ & $3 \cdot 38^{*} * *$ & $12 \cdot 47 * * *$ & $-1 \cdot 37 *$ \\
CS addition 5R & $(-)$ & 0.93 & $12 \cdot 67 * * *$ & $1 \cdot 18^{\mathrm{K}}$
\end{tabular}
Spring.

$(+)$ or $(-)$ refers to whether the genotype is later $(+)$ or earlier $(-)$ than Chinese

$* P 0.05-0.01 \quad * * * P<0.001$

The $(d)$ estimates in table 2 show that nearly all the genotypes have a later ear-emergence time than Chinese Spring. Only CS tetrasomic 5D is significantly earlier than Chinese Spring and this line is also the least sensitive to vernalisation, as is indicated by the significant interaction effect relative to Chinese Spring. One of the latest lines, CS (Hope 5D), is the most sensitive to vernalisation. These marked effects of chromosome $5 \mathrm{D}$ can readily be explained, since this chromosome in Chinese Spring carries a major Spring earliness gene Vrn3 which is not present on Hope 5D (Law et al., 1976). Substitution of 5D Hope for 5D of Chinese Spring therefore delays ear emergence and increases sensitivity to vernalisation. Likewise, increased dosage of $V r n 3$ accelerates ear emergence and reduces the vernalisation requirement.

Substitutions for or increased dosages of chromosome 5A, as in CS (Cheyenne 5A), CS 5A $\left(5 \mathrm{C}^{\mathrm{u}}\right)$ and CS tetrasomic 5A, do not greatly alter ear-emergence time or vernalisation sensitivity compared with Chinese Spring. This can be explained by the epistatic effect of $V r n 3$ on 5D (Law, 1972) and the presence of the less potent allele, orn l, on Chinese Spring 5A (Law et al., 1976). Substitutions for this allele by even less potent alleles as in C.S (Cheyenne 5A) and CS 5A (5Civ) (Law et al., 1976), or increased dosages of this allele as in CS tetrasomic $5 \mathrm{~A}$, will therefore be expected to have small effects on ear emergence.

CS addition $5 \mathrm{C}^{\mathrm{u}}$ is later than Chinese Spring and rather surprisingly is also less sensitive to vernalisation. The reasons for this are not clear since in all the other cases it is the chromosome delaying maturity which is the most sensitive. The $5 \mathrm{R}^{\mathbf{k}}$ chromosome appears to have little influence on the behaviour of CS addition $5 \mathrm{R}^{\mathrm{k}}$.

CS ovata is as late as CS (Hope 5D) but is much less sensitive to vernalisation. Evidently this cytoplasm has a major delaying effect on maturity and this delay is relatively uninfluenced by vernalisation.

\section{(ii) Cold resistance}

Table 3 gives the mean conductance for each of the nine genotypes and their differences from Chinese Spring. Since a higher conductance (lower resistance) indicates that a genotype is less resistant to freezing, it is apparent 
that at $-6^{\circ} \mathrm{C} / 14$ days CS ovata, CS tetrasomic $5 \mathrm{~A}$ and CS tetrasomic 5D are all more susceptible than Chinese Spring, while CS (Hope 5D) is more resistant. Under the $-12^{\circ} \mathrm{C} / 28$-day regime CS ovata and CS tetrasomic $5 \mathrm{~A}$ again appear more susceptible than Chinese Spring, whereas CS (Cheyenne 5A) is much more resistant.

\section{TABLE 3}

Mean conductance following freezing of nine wheat genotypes under two freezing regimes

\begin{tabular}{|c|c|c|c|c|}
\hline \multirow[b]{2}{*}{ Genotype } & \multicolumn{2}{|c|}{$-6^{\circ} \mathrm{C}, 14$ days } & \multicolumn{2}{|c|}{$-12^{\circ} \mathrm{C}, 28$ days } \\
\hline & Mean & Diff. from CS & Mean & Diff. from CS \\
\hline CS & $48 \cdot 83$ & - & $70 \cdot 40$ & - \\
\hline CS ovata & $52 \cdot 90$ & $+4.07 *$ & $72 \cdot 53$ & $+2 \cdot 13 *$ \\
\hline CS (Hope 5D) & 44.73 & $-4 \cdot 10^{*}$ & $71 \cdot 60$ & $+1 \cdot 20$ \\
\hline CS (Cheyenne 5A) & $48 \cdot 58$ & $-0 \cdot 25$ & $64 \cdot 64$ & $-5 \cdot 76 * * *$ \\
\hline $\mathrm{CS} 5 \mathrm{~A}\left(5 \mathrm{Gu}^{\mathrm{u}}\right)$ & $48 \cdot 66$ & $-0 \cdot 17$ & $72 \cdot 02$ & $+1 \cdot 62$ \\
\hline $\mathrm{CS}$ tetrasomic $5 \mathrm{~A}$ & $52 \cdot 53$ & $+3 \cdot 70^{*}$ & $72 \cdot 88$ & $+2 \cdot 48^{*}$ \\
\hline $\mathrm{CS}$ tetrasomic 5D & $55 \cdot 67$ & $+6 \cdot 84 * * *$ & $72 \cdot 20$ & $+1 \cdot 80$ \\
\hline $\mathrm{CS}$ addition $5 \mathrm{C}^{\mathrm{u}}$ & $51 \cdot 38$ & $+2 \cdot 55$ & 71.03 & +0.63 \\
\hline \multirow[t]{3}{*}{ CS addition $5 \mathrm{R}^{\mathrm{k}}$} & $48 \cdot 33$ & $-0 \cdot 50$ & $69 \cdot 03$ & $-1 \cdot 37$ \\
\hline & \multicolumn{2}{|c|}{$($ L.S.D. $=3.51)$} & \multirow{2}{*}{\multicolumn{2}{|c|}{$($ L.S.D. $=1.94)$}} \\
\hline & 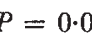 & $* *$ & & \\
\hline
\end{tabular}

(iii) Relationship between vernalisation requirement and cold resistance

Examination of the relationship between the estimates of vernalisation requirement $(g)$ and mean conductance for each genotype under a given freezing regime gave no significant correlation $(r=-0.39 \pm 0.37$, $\mathrm{P} 0.5-0.3$ for the $-6^{\circ} \mathrm{C} / 14$-day regime and $\mathrm{r}=0.09 \pm 0.38, \mathrm{P} 0.9-0.8$ for the $-12^{\circ} \mathrm{C} / 28$-day regime).

\section{Discussion}

The responses of the majority of the genotypes to vernalisation, as measured here by the parameter $g$, agree with previous reports (loc. cit) and can be explained by allelic substitutions at or increased dosages of the $V r n 1$ and $V r n 3$ loci on chromosomes $5 \mathrm{~A}$ and 5D. The most interesting vernalisation response occurs for CS ovata, where the chromosomal constitution is identical to Chinese Spring but the cytoplasms are different. The vegetative phase in both the vernalised and unvernalised treatments of CS ovata is considerably prolonged in comparison to that of Chinese Spring. (Differences between ear-emergence times in the vernalised and unvernalised treatments are 21.00 and 30.33 days respectively; L.S.D. at $\mathrm{P}=0.001$ is 3.29 days.) Cytoplasmic differences therefore have a considerable influence on rates of plant development. This influence, however, is less sensitive to vernalisation than the changes in the group 5 chromosomes which are the major determinants of the capacity of genotypes to respond to vernalisation in this experiment.

At a minimum temperature of $-6^{\circ} \mathrm{C}, \mathrm{CS}$ (Hope 5D) shows a significantly better freezing resistance than Chinese Spring, while CS tetrasomic 5A, CS 
tetrasomic 5D and CS ovata are more susceptible to cold damage. This last result is not altogether unexpected in view of the known influence of cytoplasmic factors on the cold resistance of plants (Levitt, 1956), and suggests that these may be at least as important as chromosomal differences in determining the susceptibility of a particular line.

That chromosomal as well as cytoplasmic differences influence the character is illustrated by the behaviour of CS (Hope 5D), from which it is apparent that the alleles carried on 5D of Hope are different from those in Chinese Spring and that they determine a much greater resistance to freezing to $-6^{\circ} \mathrm{C}$. Chromosomal effects are also shown by the fact that increasing the dosage of both the 5A and 5D chromosomes lowers the cold resistance of Chinese Spring, implying that they carry genes which are in some way antagonistic to a high freezing tolerance.

Results from the $-12^{\circ} \mathrm{C} / 28$-day test are rather different from those obtained at $-6^{\circ} \mathrm{C} / 14$ days in that the advantage of CS (Hope 5D) over Chinese Spring disappears under this regime while CS (Cheyenne 5A) appears much more resistant. CS ovata and CS tetrasomic 5A are again more susceptible than Chinese Spring. These findings must be interpreted as meaning that chromosome $5 \mathrm{~A}$ has alternative alleles for freezing resistance in Chinese Spring and Cheyenne, and that the latter determine the higher level of resistance. A final difference between experiments is that where the dosage of chromosome $5 \mathrm{~A}$ is increased, resistance is reduced in both the $-6^{\circ}$ and $-12^{\circ} \mathrm{C}$ tests, where this is true only at $-6^{\circ} \mathrm{C}$ in the case of $5 \mathrm{D}$.

It is unfortunate that two effects, those of freezing temperature and hardening time, have been confounded in the overall experiment, since the behaviour of particular genotypes can be equally well interpreted in two ways. Thus in the case of the $5 \mathrm{D}$ gene or genes, either the alleles differ in their effects only at relatively high temperatures $\left(-6^{\circ} \mathrm{C}\right.$ cf. $\left.-12^{\circ} \mathrm{C}\right)$, or their differences disappear when the hardening period is extended. Similarly, the alleles on 5A may produce different effects only at low temperatures or the advantage of the Cheyenne allele is revealed only under prolonged hardening.

Analysis reveals no statistically significant correlation between the two parameters used to estimate vernalisation requirement and cold resistance. Interpretation of this finding faces the difficulty that it is not known how far the parameters used in the analysis are accurate measures of the characters they purport to assess. In the case of freezing resistance, it may be that the electrical resistance of a seedling leaf after freezing does not accurately indicate the hardiness of a variety in the field. In the past, however, the method has reliably and consistently differentiated genotypes on the basis of their ability to withstand sub-zero temperatures (Jenkins and Roffey, 1974), and it must also be true that an ability to withstand direct freezing contributes to the cold tolerance of an individual.

The conclusion may be drawn that there is no relationship between vernalisation requirement and cold resistance in the genotypes examined here. In spite of the involvement of group 5 chromosomes in the control of both characters, it is unlikely that the same genetic factors are involved, and this opens up the possibility of selecting independently for the two attributes. Should the demands of agriculture make it desirable, it would ultimately be possible to develop winter wheats with good hardiness and a low vernalisation requirement. 
Acknowledgments.-One of us (C. C.) wishes to acknowledge the financial support of the Ministry of Agriculture, Fisheries and Food.

\section{ReFERENCES}

Andersson, G. 1935. Auslese von winterfesten Transgressionen bei Wintergerste durch Gefrierversuche. Zuchter, 7, 254-260.

BARES, I., SEGETA, V., AND VLASÁK, M. 1973. A contribution to the possibilities of increasing winter resistance in breeding productive varieties of wheat. Rost. Vyraba, 19(6), 573-581. (In Plant Breeding Abstr. (1973), 43(12), 776).

BECKER, J., FUCHS, W. H., AND JAPHA, B. 1947. Grundlagen und Erfahrungen der Züchtung winterfester Weizen. Zuchter, 17, 235-240.

GULYAEV, G. V., AND MAGUROV, P. F. 1973. Hereditary variation in length of vernalisation period in winter wheat varieties. Izvestiya Tim. Sel'sk. Akad, 2, 64-72. (In Plant Breeding Abstr. (1974), 44(10), 553).

HALLORAN, G. M., AND BOYDELL, G. w. 1967. Wheat chromosomes with genes for vernalisation response. Can. J. Genet. Cytol., 9, 632-639.

HAYES, H. K. 1927. Inheritance of winter hardiness and growth habit in crosses of Marquis with Minhardi and Minturki wheats. F.Agr. Research, 35(3), 223-236.

JENKINS, G., AND ROFFEY, A. P. 1974. A method of estimating the cold hardiness of cereals by measuring electrical conductance after freezing. 7. agri. Sci., Camb., 83, 87-92.

LAw, c. N. 1966. The location of genetic factors affecting a quantitative character in wheat. Genetics, 53, 487-498.

LAW, c. N. 1972. The analysis of inter-varietal chromosome substitutions in wheat and their first generation hybrids. Heredity, 28, 167-179.

LAW, c. N., And Jenkins, G. 1970. A genetic study of cold resistance in wheat. Genet. Res., Camb., 15, 197-208.

LAW, G. N., OTLOWSKA, D., AND WORLAND, A. J. 1974. The genetic control of vernalisation requirement and photoperiodic response. EWAC Newsletter, No. 4, 19-22.

LAW, C. N., WORLAND, A. J., AND GIORGI, B. 1976. The genetic control of ear emergence time by chromosomes $5 \mathrm{~A}$ and $5 \mathrm{D}$ of wheat. Heredity, 36(1), 49-58.

LevitT, J. 1956. The Hardiness of Plants. Academic Press, London.

MARTINIc, z. 1974. In Proc. 1st. FAO/SIDA Seminar for Plant Scientists from Africa and the Near East, Cairo, Egypt, Sept. 1973. Rome, Italy. FAO (1974), 351-360.

MAther, K., AND JiNKs, J. L. 1971. Biometrical Genetics. Chapman and Hall Ltd., London.

MAYSTRENKO, O. I. 1974. Identification of chromosomes carrying genes $\operatorname{Vrn} 1$ and $\operatorname{Vrn} 3$ inhibiting winter habit in wheat. EWAC Newsletter, No. 4, 49-52.

NILSSON-EHLE, H. 1912. Zur Kenntnis der Erblichkeits verhältnisse der Eigenshaft Winterfestigkeit beim Weizen. Zeit. für Pflanzenzüchtung, 1, 3-12.

Pugsley, A. T. 1971. A genetic analysis of the spring-winter habit of growth in wheat. Aust. 7. Agric. Res., 22, 21-31.

PUGSLEY, A. T. 1972. Additional genes inhibiting winter habit in wheat. Euphytica, 21, 547-552.

SNEDECOR, G. w., AND COCHRAN, w. G. 1967. Statistical methods (6th edition). The Iowa State Univ. Press, Ames, Iowa, U.S.A.

WORZELLA, w. w. 1935. Inheritance of cold resistance in winter wheat, with preliminary studies on the technique of artificial freezing tests. 7. Agric. Res., 50(7), 625-635. 